Originally published as:

Nielsen, S., Frank, C., Fruth, A., Spode, A., Prager, R., Graff, A., Plenge-Bönig, A., Loos, S., Lütgehetmann, M., Kemper, M.J., Müller-Wiefel, D.E., Werber, D.

Desperately seeking diarrhoea: Outbreak of haemolytic uraemic syndrome caused by emerging sorbitol-fermenting shiga toxin-producing Escherichia coli 0157:H-, Germany, 2009

(2011) Zoonoses and Public Health, 58 (8), pp. 567-572.

DOI: 10.1111/j.1863-2378.2011.01405.x

This is an author manuscript.

The definitive version is available at: http://onlinelibrary.wiley.com/ 


\title{
Desperately Seeking Diarrhoea: Outbreak of Haemolytic Uraemic Syndrome Caused by Emerging Sorbitol- Fermenting Shiga Toxin- Producing Escherichia coli O157:H-, Germany, 2009
}

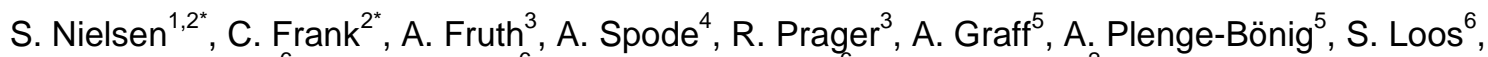 \\ M. Lütgehetmann ${ }^{6}$, M. J. Kemper ${ }^{6}$, D. E. Müller-Wiefel ${ }^{6}$ and D. Werber ${ }^{2}$ \\ ${ }^{1}$ European Programme for Intervention Epidemiology Training (EPIET), European Centre for Disease Prevention and Control (ECDC), \\ Stockholm, Sweden \\ 2 Department for Infectious Disease Epidemiology, Robert Koch Institute, Berlin, Germany \\ ${ }^{3}$ Department for Infectious Diseases, Robert Koch Institute, National Reference Centre for Salmonella and Other Bacterial Enterics, \\ Wernigerode, Germany \\ ${ }^{4}$ Local Health Department Altona, Hamburg, Germany \\ 5 Institute for Hygiene and Environment, Hamburg, Germany \\ ${ }^{6}$ University Medical Center Hamburg-Eppendorf, Hamburg, Germany
}

*Both authors contributed equally to this publication.

\section{Correspondence:}

Stine Nielsen. Department for Infectious Disease Epidemiology, Robert Koch Institute,

DGZ-Ring 1, Berlin 13086, Germany. Tel.: +49 (0) 3018754 3741; Fax: +49 (0) 3018754 3533;

E-mail: nielsens@rki.de

\begin{abstract}
Summary
Infection with sorbitol-fermenting Shiga toxin-producing Escherichia coli O157:H- (sf STEC O157:H-) is rare, but emerging in Europe. The pathogen is typically isolated from paediatric patients with life-threatening haemolytic uraemic syndrome (HUS). It is unclear whether this observation primarily reflects the pathogen's virulence or its complex laboratory diagnosis, not routinely conducted in diarrhoeal patients. In summer 2009, four boys living in the same suburb in Germany developed diarrhoea-associated HUS: three were infected by sf STEC O157:H- and one died. We conducted two analytical epidemiological studies, an extensive search for diarrhoeal cases in potentially exposed groups, and an environmental investigation. Outbreak cases were residents of the suburb diagnosed with HUS, sf STEC 0157:H- infection, or both between 24 July 2009 and 25 August 2009. Overall, we ascertained eight cases with a median age of 4 years (range: from 8 months to 9 years). Stool screening of 220 persons led to the identification of only four additional cases: two asymptomatic carriers and two diarrhoeal cases. HUS was strongly associated with visiting a local playground in July, particularly on 16th July (odds ratio $=42.7, P=0.002$ ). No other commonality, including food, was identified, and all environmental samples $(n=24)$ were negative. In this localized non-foodborne outbreak, the place of likely infection was a local playground. Sf STEC O157:Hinfection apparently limits itself rarely to diarrhoeal illness and progresses frequently to HUS. Therefore, detection of and response to this hypervirulent pathogen primarily relies on HUS surveillance.
\end{abstract}

\section{Introduction}

Shiga toxin-producing Escherichia coli (STEC) O157:H7 infection cause acute, often bloody, diarrhoea in many parts of the world. In children, STEC O157:H7 is the leading cause of haemolytic uraemic syndrome (HUS), a life-threatening condition presenting with the combination of microangiopathic haemolytic anaemia, thrombocytopenia and acute renal failure (Tarr et al., 2005). The inability to ferment sorbitol within $24 \mathrm{~h}$ facilitates widely used, timely and inexpensive culture identification of STEC 0157:H7 (Gould et al., 2009a). The main reservoir is cattle and the bacteria cause both localized and diffuse outbreaks that are often foodborne (Griffin and Tauxe, 1991; Rangel et al., 2005). Approximately $10-15 \%$ of children under 10 years of age who are diagnosed with STEC 0157:H7 infection develop HUS (Tarr et al., 2005; Gould et al., 2009b). Consequently, for every paediatric HUS patient infected by STEC O157:H7, one expects another six to nine infected patients presenting 'only' with diarrhoeal illness.

In contrast, sorbitol-fermenting (sf) STEC 0157:H- have been described in just a limited number of countries. No selective or differential media are available for their culture hampering routine diagnosis (Bielaszewska et al., 2007). The pathogen has caused several outbreaks in Germany since 1988 (Karch et 
al., 1990; Ammon et al., 1999; Alpers et al., 2009). Most of these outbreaks had a protracted case occurrence, were geographically dispersed, and encompassed between 6 and 38 cases of HUS. Sf STEC O157: $\mathrm{H}$ - appears to be emerging in other parts of Europe (Orth et al., 2009; The Norwegian Institute of Public Health, 2009; Pollock et al., 2010) as well. Outbreaks with this pathogen are usually recognized by an unexpected increase in the number of paediatric HUS patients (HUS outbreaks), apparently not paralleled by an increase in STEC-associated diarrhoea. As the reservoir of this pathogen is still unknown, previous investigations focused primarily on identifying the source of infection, not on assessing the extent of associated diarrhoeal illness (without HUS), which may go unrecognized because of difficulties in identifying the organism. However, without knowledge of the rate of accompanying milder disease courses, the true virulence of the organism is hard to gauge.

In Germany, between 26 July 2009 and 4 August 2009, four boys aged 2-9 years living within $2 \mathrm{~km}$ of each other in a Hamburg suburb developed diarrhoea-associated HUS caused by sf STEC O157:H-; one died. The suburb is densely populated with numerous multi-unit buildings separated by greenways. No farms or petting zoos are nearby. An investigation was initiated on 5 August 2009 to identify the source of infection, control the outbreakand delineate its extent. A particular goal was to determinethe number of diarrhoeal cases (without HUS) associated with sf STEC O157 infections in this outbreak.

\section{Methods}

We conducted explorative interviews and two analytical epidemiological studies, an extensive search for cases of diarrhoeal illness in potentially exposed groups, and an environmental investigation, aimed at finding the source of the outbreak. In this outbreak, a case was defined as illness in a resident of the suburb who was diagnosed with HUS or sf STEC O157:H- infection regardless of symptoms between 24 July 2009 and 25 August 2009. HUS was defined as acute haemolytic anaemia (haemoglobin level $<10 \mathrm{~g} / \mathrm{dl}$ ) with microscopic evidence of fragmented erythrocytes, thrombocytopenia (platelet count < platelets/l) and acute renal failure (increased serum creatinine above the upper limit of normal age) (Gerber et al., 2002).

Parents of the four HUS patients were interviewed with a specifically designed trawling questionnaire. An agerestricted case-control study was conducted to investigate the association between HUS and a local outdoor playground, which all four HUS patients had visited shortly before symptom onset. A case in this study was defined as an outbreak case with HUS (other outbreak cases were not known at the time of this study). Eligible controls were residents of the suburb aged 2-10 years who were identified through day-care centres and communitydistributed flyers. In addition, a cohort study conducted in day care A, which two HUS patients attended, examined whether children visiting the playground on $16^{\text {th }}$ July were at increased risk for any parent-reported diarrhoea in the 3 weeks following that visit. Thus, besides also investigating the association between playground visit and being a case (defined as any parent-reported diarrhoea), this study assessed to what extent the hypothesized exposure to sf STEC 0157 led to an increase of diarrhoeal illness. In the case-control study, bivariate exact logistic regression was used. In the cohort study, we computed bivariate risk ratios $(R R)$ and assessed statistical significance using Fisher's exact test. Stata ${ }^{(}$(v11, StataCorp, College Station, TX, USA) was used in the analysis throughout. $P$-values $<0.05$ were considered statistically significant.

Based on information from the trawling interviews, we collected stool samples and information on exposures and symptoms from the following groups: (1) household contacts of the HUS patients, (2) children and staff from day care A and (3) children and staff from day care B, located at the playground. As there was supervision of the playground performed by staff from day care $B$, lists of external visitors for each day were available for analysis. Through these lists, we identified and interviewed parents of these children (not attending day care A or B) who visited the playground on 16th July. In addition, a local paediatrician sharing time between two centrally located paediatric practices in the area was asked to compare the frequency of paediatric diarrhoea in the outbreak timeperiod with that of previous years.

We inspected the premises of the two day cares and the playground in mid-August and collected environmental samples from sandbox, wading-pool (approximately 3-6 $\mathrm{m}$ in size), toilets and toys on the playground as well as discernible animal droppings. Human and environmental samples were investigated for the presence of Shiga toxin genes (stx) at Hamburg's Hygiene Institute. Subsequently, isolated STEC were subtyped by various methods including pulsed-field gel electrophoresis (PFGE) at the German National Reference Center for Salmonella and other bacterial enterics.

\section{Results}

Overall, we ascertained eight cases with a median age of 4 years (range: from 8 months to 9 years); seven were boys. Sf STEC 0157:H- isolates from cases were indistinguishable with respect to virulence genes and PFGE pattern. 
Three HUS cases had visited the same playground on 16th July of which two had visited the playground in a group of altogether 35 children and staff from day care $A$; the third had visited the playground both on 16th July and the day before, 15th July, when a large summer party was held (with approximately 200 people) at the playground. The fourth HUS case had been there only on 21 st July. However, his - at the time of testing - stx-negative sister was at the playground on 16th July and developed diarrhoea 2 days later (Fig. 1). All four boys had played either in a wading pool $(n=3)$ or in a sandbox that had a water pump $(n=3)$. Aside from the playground visits, no common food or other overlapping exposures were revealed by the explorative interviews. In the case-control study using 25 controls ( $52 \%$ boys), HUS was strongly associated with visiting the playground in July $[4 / 4$ cases versus $6 / 25$ controls, odds ratio $=$ $13.8,95 \%$ confidence interval $(\mathrm{Cl}): 1.5-\infty, P=0.02$ ], particularly on 16 th July $(3 / 4$ cases versus $0 / 24$ controls, odds ratio $=42.7,95 \% \mathrm{Cl}: 3.7-\infty, P=0.002$ ). Retrospectively, recalculating this association both by including symptomatic primary outbreak cases without HUS (i.e. including case 6 , Fig. 1), and by excluding the possibly secondary HUS case (case 5, Fig. 1) strengthened the association even further (data not shown). In the cohort of day care A, information was available for $110(77 \%)$ of 143 children. Those who reported having visited the playground on 16 th July were more than twice as likely to report diarrhoea $(5 / 30$, $17 \%)$ than those who did not $(6 / 80,8 \% ; \mathrm{RR}=2.2,95 \% \mathrm{Cl}: 0.73-6.7, P=0.15)$. Of those five kids who visited the playground and for whom diarrhoea was reported: three were ascertained as outbreak cases and two of them had developed HUS (cases 2 and 3, Fig. 1).

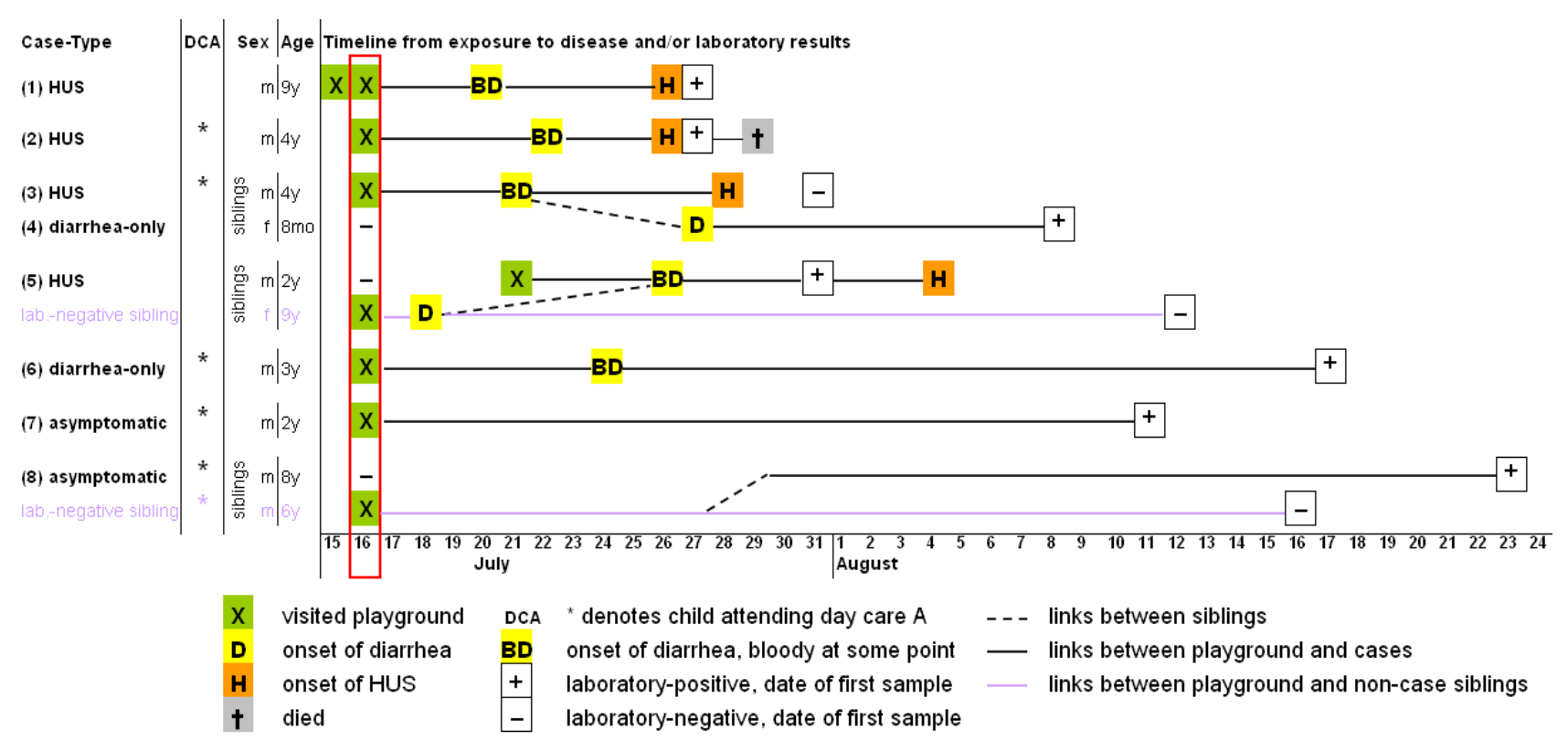

Fig. 1. Timeline from exposure to disease and/or laboratory results for the eight cases and their siblings in an outbreak of sorbitol-fermenting Shiga toxin-producing Escherichia coli O157:H-, Germany 2009.

The stool screening of 220 persons identified only four additional sf STEC O157:H- infections, of which three attended day care A. The fourth was a sibling of a HUS case (Table 1). Of those four additional cases, two reported diarrhoea (one bloody), of which an 8-month-old girl was presumably secondarily infected by her HUS-affected brother (judged by their dates of onset) and the other two were asymptomatic excreters (Fig. 1). Regarding symptoms reported in the questionnaires from the 272 potentially exposed persons, 19 (7\%) recalled diarrhoea in July: two were cases with sf STEC 0157:H- infection and 17 (6\%) tested negative for stx. None of the latter (non-cases) reported bloody diarrhoea in contrast to five of the six outbreak cases with diarrhoea. No increase in paediatric diarrhoea was noticed by the local paediatrician in this period, compared with diagnostic data from previous years.

The environmental investigation revealed that the wading pool was filled only occasionally (when the weather was very warm), and if so, was emptied the same day. No disinfection procedure was used. We found stagnant water in a sheltered compartment above the drain seal of the empty wading pool, likely mixing with fresh water upon refill. Gross faecal contamination of the wading pool or sandbox was not recalled by staff for the days in question. Few animal droppings were found on the premises. All environmental samples $(n=24)$, including those from the drain, tested negative for stx. 
Table 1: Symptoms, laboratory results and playground exposure among potentially exposed groups in an outbreak of sorbitol-fermenting Shiga toxin-producing Escherichia coli O157:H-, Germany 2009

\begin{tabular}{|c|c|c|c|c|c|c|c|}
\hline & Total & $\begin{array}{c}\text { Stool } \\
\text { tested } \\
\text { (\% of } \\
\text { total) }\end{array}$ & $\begin{array}{c}\text { HUS and } \\
\text { diarrhoea, } \\
\text { laboratory } \\
\text { positive }\end{array}$ & $\begin{array}{c}\text { Diarrhoea } \\
\text { (no HUS) } \\
\text { laboratory } \\
\text { positive }\end{array}$ & $\begin{array}{l}\text { Asympto- } \\
\text { matic } \\
\text { laboratory } \\
\text { positive }\end{array}$ & $\begin{array}{c}\text { Diarrhoea } \\
\text { (no HUS), } \\
\text { laboratory } \\
\text { negative } \\
\text { (\% of total) }\end{array}$ & $\begin{array}{l}\text { Visited } \\
\text { playground } \\
\text { on 16th July }\end{array}$ \\
\hline Initial HUS patients & 4 & $4(100)$ & 4 & 0 & 0 & 0 & 3 \\
\hline Household contacts & 11 & $11(100)$ & 0 & 1 & 0 & $1(9)$ & 1 \\
\hline $\begin{array}{cl}\text { Day care } & A^{*} \text { contacts } \\
- & \text { Children } \\
- & \text { Staff }\end{array}$ & $\begin{array}{c}141 \\
27\end{array}$ & $\begin{array}{c}137(97) \\
25(93)\end{array}$ & $\begin{array}{l}0 \\
0\end{array}$ & $\begin{array}{l}1 \\
0\end{array}$ & $\begin{array}{l}2 \\
0\end{array}$ & $\begin{array}{l}8(6) \\
1(4)\end{array}$ & $\begin{array}{c}30 \\
4\end{array}$ \\
\hline $\begin{array}{cl}\text { Day care B (playground) } \\
-\quad \text { Children } \\
-\quad & \text { Staff } \\
\end{array}$ & $\begin{array}{l}30 \\
34\end{array}$ & $\begin{array}{l}20(67) \\
27(79)\end{array}$ & $\begin{array}{l}0 \\
0\end{array}$ & $\begin{array}{l}0 \\
0\end{array}$ & $\begin{array}{l}0 \\
0\end{array}$ & $\begin{array}{c}7(23) \\
0\end{array}$ & $\begin{array}{l}9 \\
6\end{array}$ \\
\hline $\begin{array}{l}\text { Others at playground on } \\
\text { 16th July } \\
\end{array}$ & $\frac{29^{\circ}}{276}$ & $\begin{array}{c}0 \\
224(81)\end{array}$ & $\overline{4}$ & $\overline{2}$ & $\overline{2}$ & $\begin{array}{c}0 \\
17(6)\end{array}$ & $\frac{29}{82}$ \\
\hline
\end{tabular}

${ }^{*}$ Two HUS patients were in day care A.

${ }^{\circ}$ Approximately 20 additional children visited the playground on 16 th July, but they could not be reached for interviews.

\section{Discussion}

In this localized non-foodborne outbreak, the epidemiological evidence suggests a local playground as the place of infection. All cases could be linked to playground attendance on the same day (Fig. 1) either through their own attendance $(n=6)$ or that of a sibling $(n=2)$. Furthermore, visiting the playground on 16 th July was strongly associated with HUS and children of day care A with that exposure were more than twice as likely to report diarrhoea as those who did not. The observation that transmission occurred primarily on one particular day and the fact that not all outbreak cases knew each other - therefore likely did not have direct contacts on that day - speaks against direct transmission from person to person as the main transmission route and rather indicates indirect 'environmental' transmission on that day. The pathogen was likely introduced to the playground by an infected person (e.g. at the summer party on $15^{\text {th }}$ July) or a nonruminant animal. Where exactly on the playground transmission occurred remains unclear. Playing in a sandbox has been identified as an important risk factor for sporadic STEC infection among German children (Werber et al., 2007). At the same time, the wading pool is biologically and anecdotally plausible (Hildebrand et al., 1996). For example, the fourth HUS case attended the playground on the day when the wading pool was refilled for the first time since 16th July, and contaminated stagnant water above the drain may still have harboured the organisms. That the boys were overrepresented among the cases remains unexplained. Investigating whether boys engaged in different activities on the playground and collecting extra environmental samples from the boys' toilet facilities did not reveal any plausible mechanisms.

Despite extensive case finding efforts in a large group of children and adults with potential similar exposures, we were unable to find more than two cases of diarrhoea (without HUS) and two children asymptomatically infected with sf STEC O157:H- in addition to the four HUS cases picked up by HUS surveillance. Consequently, less than one case of diarrhoeal illness per case of HUS was found. This is far from the reported numbers of diarrhoeal illness per case of HUS associated with STEC O157:H-. This supports the view that sf STEC 0157: $\mathrm{H}$ - is even more virulent than STEC O157:H7, that itself is considered to be singularly virulent among enteric pathogens in the developed world (Ahn et al., 2008). In accord, sf STEC 0157:H- shows increased adherence to colonic epithelial cells, possibly causing a more potent inflammatory host response (Rosser et al., 2008). Furthermore, sf STEC O157:H- infected HUS patients differ from non-sf STEC 0157 infected HUS patients by requiring a higher number of haemodialysis sessions (Pollock et al., 2010) as well as having a higher case fatality (Gerber et al., 2002; Alpers et al., 2009). In this outbreak, one of the four HUS cases died, and another one suffered from chronic kidney disease (stage 2) including hypertension and mild proteinuria, a year after disease onset. Speculations about the hypervirulence of sf STEC 0157:H- have first been put forward based on geographically dispersed outbreaks where case ascertainment of diarrhoeal cases has not been a primary focus. Thus, ascertainment may have been incomplete due to the complex diagnosis necessary to detect this pathogen, available only at few specialized laboratories. In contrast, the localized nature of the outbreak described in this manuscript presented a unique opportunity to search extensively for associated outbreak cases with a milder outcome.

Our study is subject to several limitations. The validity of the case-control study is limited by the small number of cases alone. The results therefore should be viewed as supporting the hypothesis of the playground being the place of infection rather than confirming it. As in many investigations of infectious disease outbreaks suspecting an environmental source, the inherent delay between exposure and collection of environmental samples was substantial. Considering the dry and warm weather conditions during that 
time, the chance of finding the pathogen was small based on the limited number of samples. Likewise, stool testing was conducted 3-4 weeks after exposure. Therefore, we may have missed a few symptomatic cases by our case definition requiring laboratory confirmation. However, the proportion of reported diarrhoea (7\%) by those polled was well within background levels estimated in burden of illness studies (Herikstad et al., 2002; Imhoff et al., 2004), indicating that there was no overall increase of diarrhoeal illness in potentially exposed groups.

\section{Conclusions}

The reservoir of sf STEC 0157 remains elusive. Sorbitolfermenting Shiga toxin-producing Escherichia coli $\mathrm{O} 157: \mathrm{H}$ - infection apparently limits itself rarely to diarrhoeal illness and progresses with a high probability to HUS. Consequently, a timely clinical and microbiological surveillance of paediatric HUS cases, not in place in many countries, is needed for early detection and response to this hypervirulent pathogen.

\section{Conflicts of interest}

Nothing to declare.

\section{Acknowledgements}

We are indebted to the staff at the local health department (Hamburg Altona) and at the two day cares as well as to the parents and children for their cooperation. We thank Manuel Dehnert for input on the statistical analyses, and Marion Muehlen \& Katharina Alpers (EPIET/ PAE coordinators) for instructive comments on the manuscript.

\section{References}

Ahn, C. K., E. Klein, and P. I. Tarr, 2008: Isolation of patients acutely infected with Escherichia coli O157:H7: low-tech, highly effective prevention of hemolytic uremic syndrome. Clin. Infect. Dis. 46, 1197-1199.

Alpers, K., D. Werber, C. Frank, J. Koch, A. W. Friedrich, H. Karch, M. an der Heiden, R. Prager, A. Fruth, M. Bielaszewska, G. Morlock, A. Heissenhuber, A. Diedler, A. Gerber, and A. Ammon, 2009: Sorbitol-fermenting enterohaemorrhagic Escherichia coli O157: $\mathrm{H}$ - causes another outbreak of haemolytic uraemic syndrome in children. Epidemiol. Infect. 137, 389-395.

Ammon, A., L. R. Petersen, and H. Karch, 1999: A large outbreak of hemolytic uremic syndrome caused by an unusual sorbitolfermenting strain of Escherichia coli O157:H. J. Infect. Dis. 179, 1274-1277.

Bielaszewska, M., R. Köck, A. W. Friedrich, C. von Eiff, L. B. Zimmerhackl, H. Karch, and A. Mellmann, 2007: Shiga toxin-mediated hemolytic uremic syndrome: time to change the diagnostic paradigm? PLoS One 2, e1024.

Gerber, A., H. Karch, F. Allerberger, H. M. Verweyen, and L. B. Zimmerhackl, 2002: Clinical course and the role of Shiga toxinproducing Escherichia coli infection in the hemolyticuremic syndrome in pediatric patients, 1997-2000, in Germany and Austria: a prospective study. J. Infect. Dis. 186, 493-500.

Gould, L. H., C. Bopp, N. Strockbine, R. Atkinson, V. Baselski, B. Body, R. Carey, C. Crandall, S. Hurd, R. Kaplan, M. Neill, S. Shea, P. Somsel, M. Tobin-D’Angelo, P. M. Griffin, and P. Gerner-Smidt, 2009a: Recommendations for diagnosis of shiga toxinproducing Escherichia coli infections by clinical laboratories. MMWR. Recomm. Rep. 58, 1-14.

Gould, L. H., L. Demma, T. F. Jones, S. Hurd, D. J. Vugia, K. Smith, B. Shiferaw, S. Segler, A. Palmer, S. Zansky, and P. M. Griffin, 2009b: Hemolytic uremic syndrome and death in persons with Escherichia coli O157:H7 infection, foodborne diseases active surveillance network sites, 2000-2006. Clin. Infect. Dis. 49, 1480-1485.

Griffin, P. M., and R. V. Tauxe, 1991: The epidemiology of infections caused by Escherichia coli O157:H7, other enterohemorrhagic E. coli, and the associated hemolytic uremic syndrome. Epidemiol. Rev. 13, 60-98.

Herikstad, H., S. Yang, T. J. Van Gilder, D. Vugia, J. Hadler, P. Blake, V. Deneen, B. Shiferaw, and F. J. Angulo, 2002: A populationbased estimate of the burden of diarrhoeal illness in the United States: FoodNet, 1996-1997. Epidemiol. Infect. 129, 9-17.

Hildebrand, J. M., H. C. Maguire, R. E. Holliman, and E. Kangesu, 1996: An outbreak of Escherichia coli O157 infection linked to paddling pools. Commun. Dis. Rep. CDR Rev. 6, R33-R36.

Imhoff, B., D. Morse, B. Shiferaw, M. Hawkins, D. Vugia, S. Lance-Parker, J. Hadler, C. Medus, M. Kennedy, M. R. Moore, and T. Van Gilder, 2004: Burden of self-reported acute diarrheal illness in FoodNet surveillance areas, 1998- 1999. Clin. Infect. Dis. 38(Suppl 3), S219-S226.

Karch, H., R. Wiss, H. Gloning, P. Emmrich, S. Aleksic, and J. Bockemühl, 1990: Hemolytic-uremic syndrome in infants due to verotoxin-producing Escherichia coli. Dtsch. Med. Wochenschr. 115, 489-495.

Orth, D., K. Grif, L. B. Zimmerhackl, and R. Würzner, 2009: Sorbitol-fermenting Shiga toxin-producing Escherichia coli O157 in Austria. Wien. Klin. Wochenschr. 121, 108-112.

Pollock, K. G., M. E. Locking, T. J. Beattie, H. Maxwell, I. Ramage, D. Hughes, J. Cowieson, L. Allison, M. Hanson, and J. M. Cowden, 2010: Sorbitol-fermenting Escherichia coli O157, Scotland. Emerg. Infect. Dis. 16, 881-882.

Rangel, J. M., P. H. Sparling, C. Crowe, P. M. Griffin, and D. L. Swerdlow, 2005: Epidemiology of Escherichia coli O157:H7 outbreaks, United States, 1982-2002. Emerg. Infect. Dis. 11, 603-609.

Rosser, T., T. Dransfield, L. Allison, M. Hanson, N. Holden, J. Evans, S. Naylor, R. La Ragione, J. C. Low, and D. L. Gally, 2008: Pathogenic potential of emergent sorbitol-fermenting Escherichia coli O157:NM. Infect. Immun. 76, 5598-5607.

Tarr, P. I., C. A. Gordon, and W. L. Chandler, 2005: Shigatoxin- producing Escherichia coli and haemolytic uraemic syndrome. Lancet $365,1073-1086$.

The Norwegian Institute of Public Health, 2009: Increase in the Number of EHEC Infections in Norway 2009 [Økning iantall EHECinfeksjoner i Norge 2009]. Nasjonalt folkehelseinstitutt, Oslo. Available at: http://www.fhi.no/eway/default.aspx?pid=233\&trg=MainLeft_5565\&MainArea_5661=5565:0:15,4640:1:0:0 ::0:0\&MainLeft_5565 $=5544: 80085:: 1: 5569: 1: \cdots 0: 0$ (accessed 22 March 2011).

Werber, D., S. C. Behnke, A. Fruth, R. Merle, S. Menzler, S. Glaser, L. Kreienbrock, R. Prager, H. Tschäpe, P. Roggentin, J. Bockemühl, and A. Ammon, 2007: Shiga toxinproducing Escherichia coli infection in Germany: different risk factors for different age groups. Am. J. Epidemiol. 165, 425-434. 